\title{
An ecological momentary assessment study of physical activity behaviors among mothers of toddlers from low-income households
}

\author{
Katherine L. Campbell1, ${ }^{1,3}$, Yan Wang ${ }^{2,3}$, Ann Pulling Kuhn², Maureen M. Black ${ }^{2,3,4}$ and Erin R. Hager ${ }^{2,3^{*}}$ (1)
}

\begin{abstract}
Background: Mothers of young children from low-income communities may be vulnerable to barriers associated with low physical activity. The purpose of this study was to examine associations between home environment factors and maternal physical activity among mothers of toddlers.

Methods: Mothers of toddlers $(n=200)$ recruited from low-income communities simultaneously wore an ankleplaced accelerometer and were given a personal digital assistant for ecological momentary assessment. Mothers received randomly prompted questions about their current environment, activity, and social setting several times a day over eight consecutive days. Data were analyzed using linear mixed-effects regression models with random intercepts; within-group and between-group relations between physical activity and environment factors were disaggregated.
\end{abstract}

Results: Within-group relations included higher physical activity counts for specific mothers with television off versus on $(95 \% \mathrm{Cl}=130.45,199.17)$, children absent versus present $(95 \% \mathrm{Cl}=82.00,3.43)$, engaging with a child versus not $(95 \% \mathrm{Cl}=52.66,127.63)$, and outside versus inside location $(95 \% \mathrm{Cl}=277.74,392.67)$. Between-group relations included higher physical activity on average when other adults were absent versus present $(95 \% \mathrm{Cl}=-282.63$, 46.95). Recruitment site (urban vs. semi-urban) significantly moderated the within-group relation between being outside versus inside and activity count $(\beta=-243.12,95 \% \mathrm{Cl}=-358.74,-127.47)$, and showed stronger relations among urban mothers $(\beta=440.33,95 \% \mathrm{Cl}=358.41,522.25)$, than semi-urban $(\beta=190.37,95 \% \mathrm{Cl}=109.64,271.11)$. Maternal body weight significantly moderated the within-group relation between being located outside versus inside the home and activity count ( $\beta$ for interaction $=-188.67,95 \% \mathrm{Cl}=-308.95,-68.39$ ), with a stronger relation among mothers with normal weight $(\beta=451.62,95 \% \mathrm{Cl}=345.51,557.73)$, than mothers with overweight/obesity $(\beta=271.95,95 \% \mathrm{Cl}=204.26,339.64)$.

Conclusions: This study highlights home environmental factors, including screen time, the presence of others (adults and children), and location (i.e., outside versus inside) that may relate to maternal physical activity behaviors. Understanding factors associated with physical activity could reduce physical activity disparities.

Trial registry ClinicalTrials. NCT02615158, April 2006

Keywords: Public Health, Physical Activity, Maternal Health, Ecological Momentary, Assessment

*Correspondence: ehager@som.umaryland.edu

2 Department of Pediatrics, Growth and Nutrition Division, University

of Maryland School of Medicine, Baltimore, MD 21201, USA

Full list of author information is available at the end of the article

\section{Background}

Physical activity is a central component of a healthy lifestyle for reducing poor health outcomes [1]. Only about half of US adults report that they meet the nationally 
recommended levels of physical activity (50.2\% in 2017) $[2,3]$. Disparities in physical activity level by socio-demographic factors exist, such that lower physical activity is associated with low-income status, Black race or Hispanic ethnicity, and female gender [4-11]. These associations suggest that women from low-income communities may experience barriers to meeting the recommended physical activity levels [12].

Based on the Ecological Model of Active Living, an individual's physical activity behavior is dependent on their social context and physical environment, including caregiving activities, physical location (outside vs. inside), work patterns, electronic usage, and social support [13-18]. Frequent television viewing and lack of time have been associated with low physical activity in children, whereas social support has been associated with increased physical activity in mothers of young children $[17,19]$. These social and community-level factors, in combination, may be related to physical activity behaviors among mothers of young children living in lowincome communities [15].

Ecological Momentary Assessment (EMA) is a recurrent, real-time assessment of an individual's behavior that minimizes recall bias by addressing the context in which these behaviors are occurring [20]. A recent EMA study found higher toddler physical activity when outside (versus inside; with stronger associations observed for older children versus younger), other children were nearby (versus no other children present), and engaging with the mother (versus no engagement) [21]. This manuscript extends the toddler study by examining the association between the home environment and physical activity among mothers of toddlers using the same constructs. To expand the knowledge-base on mother and toddler physical activity, we tested the hypotheses that mothers are more active when: (1) outside versus inside, (2) TV off versus on, (3) other adults present versus absent, 4) children present versus absent, and (5) engaging with their toddler versus not engaging. Further exploratory analysis examined whether recruitment site (urban versus semiurban) and Body Mass Index (BMI) moderated relations between environment factors and physical activity.

\section{Methods}

\section{Study sample}

Baseline data from the Toddler Overweight Prevention Study (TOPS), collected from 2007 to 2010, were used for this study [22]. TOPS is a randomized controlled trial that tested the effects of maternal lifestyle or responsive parenting interventions on reducing the rate of BMI increase among toddlers and mothers from urban and semi-urban areas in a Mid-Atlantic USA state [22].
We recruited samples from two sites: (1) an urban site (city of $>250,000$ ) from a primary care clinic serving a low-income community and (2) an adjacent semi-urban site (city of $<100,000$ ) from a WIC Clinic (Supplemental Nutrition Program for Women, Infants, and Children), a federal program that provides supplemental food, nutrition counseling, and referrals to women, infants, and children up to age five at nutritional risk and living below $185 \%$ of the federal poverty level $[22,23]$. Recruitment strategies included promotional flyers and in-person recruitment in clinic waiting rooms. Baseline and followup data collection took place in a laboratory setting and in the home and the interventions were conducted in community sites. Eligibility criteria for toddlers included: toddler's age 12-32 months, born at term with birth weight over $2500 \mathrm{~g}$, without health restrictions, congenital problems or developmental delays, and able to walk independently. Eligible criteria for mothers included: age 18 years or older, not pregnant, WIC-eligible, Englishspeaking, and without medical/physical conditions that limited physical activity (Physical Activity Readiness Questionnaire, PAR-Q) [24]. The TOPS study methods are described elsewhere [25]. The University of Maryland, Baltimore Institutional Review Board (HP-00040253), and Maryland State Department of Health Institutional Review Board (Protocol 06-53) approved TOPS, including all activities and procedures in this study. The mothers provided written informed consent.

\section{Measures}

\section{Sample characteristics}

At baseline, mothers were electronically surveyed on demographics and health history for themselves and their toddlers [22]. In the demographic survey, mothers reported their age, toddler age, number of children, race, marital status (i.e., unmarried, married, divorced), level of education, employment status (i.e., employed/part-time or unemployed), and annual household income. To calculate mothers' body mass index (BMI), data collectors weighed mothers (kilograms) using the TANITA 300GS (Tanita Corp) in duplicate or triplicate to the nearest $0.1 \mathrm{~kg}$ and measured their height in duplicate or triplicate to the nearest $0.5 \mathrm{~cm}$ using a Shorr measuring board (Shorr Productions). BMI was categorized as underweight $\left(\mathrm{BMI}<18.5 \mathrm{~kg} / \mathrm{m}^{2}\right)$, normal weight $(\mathrm{BMI}=18.5$ to $\left.<25 \mathrm{~kg} / \mathrm{m}^{2}\right)$, overweight $\left(\mathrm{BMI} \geq 25\right.$ to $\left.<30 \mathrm{~kg} / \mathrm{m}^{2}\right)$, and obese $\left(\mathrm{BMI} \geq 30 \mathrm{~kg} / \mathrm{m}^{2}\right)$.

\section{Ecological momentary assessment}

Home environment factors were assessed with EMA methodology. The study participants were given a personal digital assistant (PDA), PalmZ22 (Palm, Inc., Sunnyvale, CA, USA), which randomly beeped on 53 
separate occasions (8:30am to $8: 30 \mathrm{pm}$ ) over eight consecutive days to prompt participants to answer questions about their current environment, activity, and social setting [21]. The EMA methods developed for this study were pilot-tested with a small group $(n=10)$ of mothers with toddler-aged children to determine acceptability of question wording, optimal number of prompts per day, and timing of first and last prompt. Modifications were incorporated into the final protocol. When prompted via PDA, participants had 15 min to respond to the questionnaire. Participants were asked about engagement with their child only if they responded that the child was nearby (i.e. are you talking, singing, or playing with your child right now?). Participants who responded "no" to child nearby were not included in the analyses for engaging with child. Maternal response rate was calculated based on the number of EMA prompts answered out of the total possible prompts sent over the study period.

To account for the recurrent EMA prompts, personmean centering was used to find the average response for each participant and the variability of their responses. Centering involved creating a mean for each participant (average of all responses for a single construct) and measuring the deviation from each participant's personal mean for each specific response. Within-group findings represent the relationship between home environment and maternal physical activity for individual participants (i.e. the variability of physical activity of a participant, dependent on the home environment factors). Betweengroup findings represent the relationship between the home environment and physical activity across all participants (i.e. the average physical activity count for each participants' completed responses, in relation to their average reported environment factors).

\section{Accelerometry}

Physical activity was assessed using accelerometry [21]. We attached an Actical accelerometer (Phillip Respironics, Bend, OR, USA) to the non-dominant or left ankle using a non-removable hospital band placed next to the skin of the study participants [21]. The Actical accelerometer is small, waterproof, and measures movement in multiple planes. Accelerometers were worn for $>8$ days for a 24-h time period to track the mothers' and toddlers' physical activity [21]. Raw activity counts collected in 1-min epochs were used in the analysis. If a valid EMA response was recorded, accelerometry data were summed for 15 -min preceding and following the response (31 $\mathrm{min}$ in total). The outcome variable was the total accelerometer activity count surrounding the corresponding EMA responses (dependent variable). The dependent variable, activity counts over 31 min surrounding each beep $( \pm 15 \mathrm{~min}$ ), was skewed (skewness $=3.59)$; we conducted log transformation to normalize the data. The log transformed and non-transformed outcomes were examined, and the findings matched regarding significance and direction; non-transformed raw activity counts were used in the analysis to facilitate interpretation. To describe the amount of time mothers spent in moderate to vigorous physical activity (MVPA) per day, the threshold of $>3200$ counts/minute was applied to the entire data collection period ( $>8$ days) [26]. The use of Actical ankle accelerometry has been found to be a valid and reliable measure of physical activity [26].

\section{Statistical analysis}

Chi-square tests for categorical variables and t-tests for continuous variables were used to assess differences in baseline characteristics and response rate between individuals included and excluded from the analysis. Response rate by prompt time (e.g. morning versus evening, weekday versus weekend) was also assessed.

Linear mixed-effects regression models with random intercepts were used to assess the real-time relation between activity counts collected using accelerometry and environmental factors based on EMA responses, accounting for the clustering of responses within each mother. Separate models assessed activity counts in relation to environmental factors ( $\mathrm{TV}$ on/off, presence of adults, presence of children, engagement with child, physical location) based on EMA responses, respectively. Recruitment site, number of children, time of day, age, and maternal BMI were included in the models as covariates [27]. Race/ethnicity was highly correlated with recruitment site and therefore was excluded as a covariate to avoid collinearity (non-Hispanic White/other compared to urban/semi-urban $\mathrm{r}=0.63 ; \mathrm{p}<0.001$ ).

We explored the moderating effects of recruitment site and maternal BMI on the relations between each home environment factor and activity counts, by including the interaction terms in the models. The moderating effect of engaging (i.e. talking, singing, playing) with the child was also explored using similar models with interaction terms for between-group and within-group relations, separately. Stratified analyses by recruitment site and by maternal weight followed if significant interactions existed (Table 4). SPSS (IBM SPSS Statistics 22) and SAS 9.4 statistical software (SAS Institute Inc, Cary, NC, USA) were used for the analyses.

\section{Results}

\section{Sample characteristics}

The analysis sample included 200/285 mothers (inclusion rate $=70 \%$ ) with matched EMA and physical activity data. Reasons for missing data were: incomplete or missing accelerometry data $(n=48)$, incomplete or missing 
EMA data $(n=24)$, or EMA/accelerometry data did not overlap $(n=13)$.

The sample is described in Table 1. The median age was 26.2 years old and the majority of mothers identified as Black (62\%). Many of the mothers were living at or below the federal poverty ratio (67\%), unmarried (66\%), having overweight/obesity (72\%), and had two or more children in the household (median of 2.0 children). The median daily MVPA was 20.2 min. Compared to included participants, excluded participants were more likely to reside in the semi-urban versus urban site $(45.5 \%$ vs $27.9 \%$, $\mathrm{p}<0.001)$ and less likely to be Black versus white $(62.0 \%$ vs $80.5 \%, \mathrm{p}<0.001)$.

\section{Ecological momentary assessment (EMA)}

Among the 200 participants with matched EMA and accelerometer data, 3082 individual EMA responses were recorded that aligned with surrounding accelerometer data and comprised the analysis sample data (see Table 2). Using a denominator of 10,600 possible beeps (200 participants $\times 53$ maximum possible prompts), EMA response rate for the study population was 39\% (4106 answered prompts $/ 10,600$ possible prompts sent). Maternal response rate for the sample ranged from 4 to $85 \%$. The mean number of responses per participant was 21 , ranging from 2 to 45 responses. The distribution of responses across time of day includes $26.2 \%$ of responses in the morning (0830-1159), $28.8 \%$ in the afternoon (1200-1559) and $45.1 \%$ in the evening (1600-2030). There was no significant difference in response rates between participants with or without accelerometer data. Participants were asked about engagement with their child only if they responded that the child was nearby (i.e. are you talking, singing, or playing with your child right now?). Participants who responded "no" to child nearby were deleted from the analyses for engaging with child.

Table 1 Sample description $(N=200)$

\begin{tabular}{|c|c|c|}
\hline \multicolumn{3}{|l|}{ Median (IQR) or N (\%) } \\
\hline Maternal age & Years & $26.2(7.7)$ \\
\hline Toddler age & Months & $19.8(9.5)$ \\
\hline Household composition & Number of children & $2.0(2.0)$ \\
\hline \multirow[t]{2}{*}{ Physical Activity } & Activity counts (counts $\min ^{-1}$ ) & $291.2(138.1)$ \\
\hline & MVPA (minutes/day) & $20.2(19.1)$ \\
\hline \multirow[t]{4}{*}{ Maternal race } & Non-Hispanic Black or African-American & $124(62.0 \%)$ \\
\hline & Hispanic or Latino & $7(3.5 \%)$ \\
\hline & Non-Hispanic White or Caucasian & $62(31.0 \%)$ \\
\hline & Other & $7(3.5 \%)$ \\
\hline \multirow[t]{4}{*}{ Maternal body size } & Underweight $\left(\mathrm{BMI}^{\mathrm{a}}<18.5\right)$ & $2(1.5 \%)$ \\
\hline & Healthy weight $(18.5 \leq \mathrm{BMI}<25)$ & $54(26.9 \%)$ \\
\hline & Overweight $(25 \leq \mathrm{BMI}<30)$ & $40(20.3 \%)$ \\
\hline & Obese $(\mathrm{BMI} \geq 30)$ & $101(51.3 \%)$ \\
\hline \multirow[t]{3}{*}{ Marital status } & Unmarried & $132(66.0 \%)$ \\
\hline & Married & $59(29.5 \%)$ \\
\hline & Divorced & $9(4.5 \%)$ \\
\hline \multirow[t]{4}{*}{ Education } & Less than high school & $34(17.0 \%)$ \\
\hline & High school diploma/equivalent & $69(34.5 \%)$ \\
\hline & Some college & $68(34.0 \%)$ \\
\hline & College or graduate degree & $29(14.5 \%)$ \\
\hline \multirow[t]{2}{*}{ Employment } & Employed/Part-time & $72(36.0 \%)$ \\
\hline & Unemployed & $128(64.0 \%)$ \\
\hline \multirow[t]{2}{*}{ Socioeconomic status } & Living above federal poverty ratio & $65(32.5 \%)$ \\
\hline & Living at/below federal poverty ratio & $130(65.0 \%)$ \\
\hline \multirow[t]{2}{*}{ Recruitment location } & Semi-urban & $91(45.5 \%)$ \\
\hline & Urban & $109(54.5 \%)$ \\
\hline \multirow[t]{2}{*}{ Toddler age } & $\leq 24$ months & $147(73.5 \%)$ \\
\hline & $>24$ months & 52 (26.0\%) \\
\hline
\end{tabular}

${ }^{a}$ BMI (body mass index) 
Table 2 Ecological momentary assessment responses (Responses $=3082 ; \mathrm{N}=200$ )

\begin{tabular}{llc}
\hline Factor & Question & Response Options \\
\hline Television On/Off & Is the TV on in the area? & No; yes \\
Adults Present & How many adults are in the room/area? & $0 ; 1$ or more \\
Children Present & How many children are in the room/area? & $0 ; 1$ or more \\
Interaction with Child & Are you talking, singing, or playing with your child right & No; yes (yes) \\
& now? & Are you... \\
Physical Location & & Inside; outside \\
\hline
\end{tabular}

\section{Physical activity and environment}

Within-group analyses showed significance for four environment factors in relation to physical activity over $30 \mathrm{~min}$ (see Table 3). TV off versus on was associated with 165 more counts of physical activity $(95 \% \mathrm{CI}=130.45$, 199.17). Not having a child nearby versus having a child nearby was associated with 43 more counts of physical activity $(95 \% \mathrm{CI}=82.00,3.43)$. Engaging with a child versus no engagement was associated with 90 more counts of physical activity $(95 \% \mathrm{CI}=52.66,127.63)$. Outside versus inside location was associated with 335 more counts of physical activity $(95 \% \mathrm{CI}=277.74,392.67)$. The only hypothesized factor not associated with physical activity in within-group analyses was the presence of other adults nearby.

Between-group analyses were significant for a single factor (see Table 3). The accompaniment of other adults versus no other adults was associated with 165 fewer counts of physical activity over $30 \mathrm{~min}$ on average $(95 \% \mathrm{CI}=-282.63,-46.95)$. Hypothesized factors not associated with physical activity in between-group analyses include TV on versus off, being near a child versus not being near a child, engaging with a child versus not engaging with a child (if a child is reported to be nearby), or outside versus inside location.

\section{Moderating effects}

Recruitment site significantly moderated the withingroup relation between being outside versus inside and activity count $(\beta=-243.12$ for interaction, $95 \% \mathrm{CI}=-$ $358.74,-127.47$ ) (see Table 4). Based on stratified analysis, relations between outside location and activity count were stronger among urban mothers $(\beta=440.33$, 95\% $\mathrm{CI}=358.41,522.25)$, than among semi-urban mothers $(\beta=190.37,95 \% C I=109.64,271.11)$. Across both sites, mothers' activity counts were higher when they were outside versus inside.

Maternal body weight significantly moderated the within-group relation between outside versus inside and activity count $(\beta$ for interaction $=-188.67,95 \%$ $\mathrm{CI}=-308.95,-68.39)$. A stratified analysis by maternal weight status found that the relation between outside

Table 3 Associations between physical activity and environment factor using unadjusted and adjusted linear mixed-effects regression models

\begin{tabular}{|c|c|c|c|c|c|c|c|c|}
\hline & \multicolumn{4}{|l|}{ Unadjusted Model $^{\mathrm{a}}$} & \multicolumn{4}{|l|}{ Adjusted Modelab } \\
\hline & \multicolumn{2}{|l|}{ Between subject } & \multicolumn{2}{|l|}{ Within subject } & \multicolumn{2}{|l|}{ Between subject } & \multicolumn{2}{|l|}{ Within subject } \\
\hline & $\begin{array}{l}\beta \\
(95 \% \mathrm{Cl})\end{array}$ & $p$ & $\begin{array}{l}\beta \\
(95 \% \mathrm{Cl})\end{array}$ & $p$ & $\begin{array}{l}\beta \\
(95 \% \mathrm{Cl})\end{array}$ & $p$ & $\begin{array}{l}\beta \\
(95 \% \mathrm{Cl})\end{array}$ & $p$ \\
\hline Television: off & $\begin{array}{l}146.41 \\
(21.35,271.47)\end{array}$ & 0.022 & $\begin{array}{l}164.60 \\
(130.25,198.94)\end{array}$ & $<.001$ & $\begin{array}{l}121.02 \\
(-6.83,248.88)\end{array}$ & 0.063 & $\begin{array}{l}164.81 \\
(130.45,199.17)\end{array}$ & $<.001$ \\
\hline Adults nearby: no & $\begin{array}{l}151.51 \\
(31.24,271.78,)\end{array}$ & 0.014 & $\begin{array}{l}-9.26 \\
(-44.92,26.41)\end{array}$ & 0.611 & $\begin{array}{l}164.79 \\
(46.95,282.63)\end{array}$ & 0.006 & $\begin{array}{l}-11.34 \\
(47.31,24.62)\end{array}$ & 0.536 \\
\hline Children nearby: no & $\begin{array}{l}40.54 \\
(-90.62,171.70)\end{array}$ & 0.543 & $\begin{array}{l}45.21 \\
(6.06,84.35)\end{array}$ & 0.024 & $\begin{array}{l}41.50 \\
(-87.61,170.62)\end{array}$ & 0.527 & $\begin{array}{l}42.71 \\
(3.43,82.00)\end{array}$ & 0.033 \\
\hline Engaging with child: yes & $\begin{array}{l}-25.68 \\
(-189.30,137.94)\end{array}$ & 0.757 & $\begin{array}{l}88.23 \\
(50.79,125.67 .39)\end{array}$ & $<.001$ & $\begin{array}{l}-13.77 \\
(-180.45,152.91)\end{array}$ & 0.871 & $\begin{array}{l}90.15 \\
(52.66,127.63)\end{array}$ & $<.001$ \\
\hline Physical Location: Outside & $\begin{array}{l}202.42 \\
(-105.64,510.48)\end{array}$ & 0.197 & $\begin{array}{l}333.89 \\
(276.52,391.26)\end{array}$ & $<.001$ & $\begin{array}{l}258.48 \\
(-45.50,562.47)\end{array}$ & 0.095 & $\begin{array}{l}335.21 \\
(277.74,392.67)\end{array}$ & $<.001$ \\
\hline
\end{tabular}

Note: Boldface indicates statistical significance $(\mathrm{p}<0.05)$

a Non-normalized activity counts are used in both models due to similarity to log-transformed activity counts

b Model adjusted for maternal age, time of day, maternal BMI, recruitment location, and number of children 
Table 4 Associations between physical activity and environment factor using interaction terms in linear mixed-effects regression models

\begin{tabular}{|c|c|c|c|c|}
\hline \multirow[t]{2}{*}{ Interaction model $^{\mathrm{a}}$} & \multicolumn{2}{|l|}{ Between subject } & \multicolumn{2}{|l|}{ Within subject } \\
\hline & $\begin{array}{l}\beta \\
(95 \% \mathrm{Cl})\end{array}$ & $p$ & $\begin{array}{l}\beta \\
(95 \% \mathrm{Cl})\end{array}$ & $p$ \\
\hline Physical Location by Recruitment Location & $\begin{array}{l}-73.48 \\
(-687.66,540.69)\end{array}$ & 0.814 & $\begin{array}{l}243.12 \\
(127.47,358.74)\end{array}$ & $<.001$ \\
\hline Semi-Urban & $\begin{array}{l}179.20 \\
(-279.21,637.61)\end{array}$ & 0.777 & $\begin{array}{l}190.37 \\
(109.64,271.11)\end{array}$ & $<.001$ \\
\hline Urban & $\begin{array}{l}324.99 \\
(-104.30,754.28)\end{array}$ & 0.136 & $\begin{array}{l}440.33 \\
(358.41,522.25)\end{array}$ & $<.001$ \\
\hline Physical Location by BMI & $\begin{array}{l}29.86 \\
(-694.77,754.50)\end{array}$ & 0.935 & $\begin{array}{l}188.67 \\
(68.39,308.95)\end{array}$ & 0.002 \\
\hline Normal & $\begin{array}{l}314.28 \\
(-187.76,816.31)\end{array}$ & 0.214 & $\begin{array}{l}451.62 \\
(345.51,557.73)\end{array}$ & $<.001$ \\
\hline Overweight/Obese & $\begin{array}{l}243.63 \\
(-131.53,618.80)\end{array}$ & 0.201 & $\begin{array}{l}271.95 \\
(204.26,339.64)\end{array}$ & $<.001$ \\
\hline Engaging with Child by BMI & $\begin{array}{l}206.67 \\
(-148.45,561.80)\end{array}$ & 0.252 & $\begin{array}{l}-21.68 \\
(-103.37,60.00)\end{array}$ & 0.603 \\
\hline Normal & $\begin{array}{l}-201.10 \\
(-438.71,36.50)\end{array}$ & 0.095 & $\begin{array}{l}104.47 \\
(33.05,175.89)\end{array}$ & 0.004 \\
\hline Overweight/Obese & $\begin{array}{l}54.79 \\
(-171.92,281.51)\end{array}$ & 0.633 & $\begin{array}{l}84.42 \\
(40.21,128.63)\end{array}$ & $<.001$ \\
\hline
\end{tabular}

Note: Boldface indicates statistical significance $(p<0.05)$

a Non-normalized activity counts are used in both models due to similarity to log-transformed activity

location and activity counts was stronger among mothers who had normal weight $(\beta=451.62,95 \% \mathrm{CI}=345.51$, $557.73)$, than among mothers who had overweight/obesity $(\beta=271.95,95 \% \mathrm{CI}=204.26,339.64)$.

There were no significant between-group moderating effects of recruitment site and maternal BMI for physical location (inside vs. outside). Maternal weight status did not moderate the within or between-group relation between engaging with a child versus not engaging and activity count. Furthermore, there was not a moderating effect for response rate.

\section{Discussion}

Using EMA in conjunction with accelerometry in real time, five factors within the Ecological Model of Active Living were tested, yielding within-group (for individual participants) and between-group (average of all participants) findings. Study findings align with the guiding model by identifying home environment factors associated with maternal physical activity such as screen time, the presence of others (i.e., adults and children), physical location (i.e., outside vs. inside) as well as moderating factors such as maternal weight status and recruitment site (i.e., urbanicity).

The within-group finding that individual participants were less active when the television was on (versus off) extends similar findings that television usage is associated with low physical activity, as reported on recall surveys $[15,28]$. In contrast, a study using the same dataset found no relation for toddler physical activity between television on versus off [21]. We did not collect data on the type of television programming and whether it was geared towards mothers or toddlers. Future research should explore the type of programming and the intended audience (mother vs. toddler) and how this may affect their physical activity levels.

Findings related to physical activity in the context of other adults varied. Across participants, mothers who reported being alone more frequently had more physical activity counts over 30 min compared to mothers who reported being with other adults. However, among individual mothers, rates of physical activity were not associated with the presence of other adults, possibly due to competing contexts of why other adults were present. For example, mothers may be with other adults at a sedentary job or with other adults who are providing social support to be physically active, as shown in other studies [18]. Future studies may prioritize understanding the context of the social setting to parse out associations with physical activity.

Contrary to expectations, individual mothers had lower activity counts when in the presence of one or more children compared to when they were alone. Previous studies have shown that maternal and child physical activity are 
associated, including a similar study on toddlers in this same population [21]. Toddlers often engage in "secure base" behaviors, in which they play in the vicinity of their caregivers, running back and forth to check-in [29], which does not require much activity for mothers to supervise their child [30]. Although when individual mothers were engaging with their child, they were more active compared to when they were together, but not engaging with their child. In the toddler study, the toddlers were also more active when engaging with the mother, supporting the connection between mother and toddler physical activity [21]. These findings suggest that mothers are most active without their toddler nearby. Future studies could examine whether mother physical activity drives toddler physical activity or vice versa, since mothers in low-income communities are exposed to barriers associated with low physical activity [12].

The finding that individual mothers and mothers on average (marginally) were more active when outside (versus inside) is consistent with the toddler study, where within individual toddlers, physical activity counts were higher when outside compared to inside [21]. Outside location could be associated with exercise or active transportation if there are yards, sidewalks, or public transit near the home that provide opportunities to be physically active [15]. In this study, the availability of green space and perhaps the accessibility and infrastructure of surrounding areas, including parks and walking paths, may encourage physical activity and active transport when outdoors $[15,31]$.

Recruitment site significantly moderated the withingroup relation between physical location and physical activity among participants. Mothers recruited from the urban site had higher activity counts when outside compared to inside, which was greater than the activity counts of mothers recruited from the semi-urban site. Prior studies have found that active transport is associated with physical activity, which may be more prevalent in the urban sample compared to the semi-urban sample [15]. Social environmental factors that may restrict physical activity, such as crime, poverty, and maintenance of infrastructure, may impact both the urban and semiurban mothers [32]. Decreased access to exercise facilities may also support these findings because mothers may be getting their activity mainly outdoors from transport, instead of exercising in a facility or indoors, as they are a relatively sedentary group [33]. Previous literature suggests that individuals of low socioeconomic status often get their physical activity from physically demanding occupations, which may apply in this sample [34].

This study found a difference in physical activity by weight status among mothers when outside versus inside such that mothers with overweight/obesity were less active when outside compared to mothers who had normal weight status. In general, adult healthy weight women are more active compared to women with overweight/obesity [27, 35]. These findings suggest that targeting active transport and more time outside of the home among mothers with overweight/obesity and their toddler age children may be an area for future intervention.

\section{Limitations}

There are limitations that should be considered. First, the direction of the relations between home environmental factors and physical activity cannot be determined in this repeated cross-sectional investigation due to the contemporary relations (15 min of physical activity before/ after prompt). Second, the mean response rate is low for EMA responses among mothers, with a wide range of response numbers per participant. However, this rate is an estimate using the maximum possible prompts available for each person as the denominator. We are unable to know if the non-responses were due to true participant non-response or due to device-related reasons, (e.g., non-functional battery) or if the device was returned before all 53 prompts reached the participant. These factors can be taken into consideration when calculating the response rate for future studies. Despite the limitations, there was not a moderating effect of participant response rate. Furthermore, the EMA questions were designed to be brief and did not require the participant to report the details of the context, only whether they were or were not in a particular setting. For example, the question asked whether the TV was on, not whether the mother or toddler were watching. Additionally, questions asked about the presence of other adults or children and whether mothers were engaged with the child, but they did not ask for information around the specifics of the activities. Given the limited number of EMA studies conducted with low-income women to understand the context of their physical activity, it is difficult to compare the current results with other studies. Therefore, future research is needed to compare how context relates to physical activity in other populations and settings. By combining other environmental measures, such as Geographic Information Systems (GIS) with EMA and accelerometry, we could gain a greater understanding of the home and community environmental context, including outdoor space, which was not examined in the current study.

\section{Conclusions}

Guided by the Ecological Model of Active Living and through a novel approach using EMA paired with accelerometry, this study identified home physical and social environment factors that were associated with maternal 
physical activity. To increase maternal physical activity, findings call for a reduction in screen time, increasing active mother-toddler engagement in play, and promoting active transport methods. Additionally, findings suggest that future interventions target mothers with overweight/obesity and from semi-urban areas as they may be particularly vulnerable to low physical activity. Understanding factors associated with physical activity during this critical period in a woman's life could help reduce disparities surrounding inactivity.

\begin{abstract}
Abbreviations
BMI: Body mass index; EMA: Ecological Momentary Assessment; MVPA: Moderate to vigorous physical activity; PDA: Personal digital assistant; SEM: Social Ecological Model; TOPS: Toddler Overweight Prevention Study (a randomized controlled trial that tested the effects of maternal lifestyle or responsive parenting interventions on reducing the rate of BMI growth among toddlers and mothers; WIC: Supplemental Nutrition Program for Women, Infants, and
\end{abstract} Children.

\section{Acknowledgements}

We acknowledge the TOPS participants and data collection team, including Raquel Arbaiza, Adrienne Burroughs, and Brian Merry.

\section{Authors' contributions}

$\mathrm{EH}$ and $\mathrm{MB}$ conceptualized study design, led study implementation, managed the study, and contributed to manuscript writing. KC led manuscript writing and statistical analysis with support from YW. YW supported statistical analysis and contributed to manuscript writing. AK contributed to manuscript writing and finalizing content for submission. All authors read and approved the final manuscript.

\section{Funding}

Data collection was supported by US Department of Agriculture (grant no. CREES 2005-04808) (Black), NICHD (R01HD056099) (Black). IRB no.: HP-00040253, and Mid Atlantic Nutrition Obesity Research Center (5P30DK072488) Pilot and Feasibility Grant (Hager). Data analysis and manuscript preparation was supported by NICHD (R03HD073802) (Hager), NICHD University of Maryland's Organized Research Effort in Women's Health BIRCWH K12 Scholar Program (K12HD43489-8), and University of Maryland Baltimore Institute for Clinical and Translational Research (ICTR) which is funded in part by Grant Number TL1 TR003100 from the National Center for Advancing Translational Sciences (NCATS) a component of the National Institutes of Health $(\mathrm{NIH})$, and NIH Roadmap for Medical Research. The contents are solely the responsibility of the authors and do not necessarily represent the official view of the University of Maryland Baltimore ICTR, NCATS or NIH.

\section{Availability of data and materials}

The datasets used and/or analyzed during the current study are available from the corresponding author upon reasonable request.

\section{Declarations}

\section{Ethics approval and consent to participate}

Ethics approval for this study was obtained from the University of Maryland, Baltimore Institutional Review Board (HP-00040253) and the Maryland Department of Health Institutional Review Board (Protocol 06-53). Administrative permissions were not required to access and use the data described in this study. The mothers provided written informed consent.

\section{Consent for publication}

Not applicable.

\section{Competing interests}

The authors declare that they have no competing interests.

\section{Author details}

${ }^{1}$ Department of Biology, Emory University, Atlanta, GA 30322, USA. ${ }^{2}$ Department of Pediatrics, Growth and Nutrition Division, University of Maryland School of Medicine, Baltimore, MD 21201, USA. ${ }^{3}$ Department of Epidemiology and Public Health, University of Maryland School of Medicine, Baltimore, MD 21201, USA. ${ }^{4}$ RTI International, Research Triangle Park, NC 27709, USA.

Received: 8 September 2020 Accepted: 24 February 2021

Published online: 22 March 2021

\section{References}

1. Lee IM, Shiroma EJ, Lobelo F, Puska P, Blair SN, Katzmarzyk PT. Effect of physical inactivity on major non-communicable diseases worldwide: an analysis of burden of disease and life expectancy. Lancet. 2012;380(9838):219-29.

2. Prevention CfDC. BRFSS Prevalence \& Trends Data. In: National Center for Disease Prevention and Health Promotion DoPH, editor. 2015.

3. Physical Activity Guidelines for Americans. In: Services UDoHaH, editor. 2nd ed. Washington DC2018.

4. Shuval K, Li Q, Gabriel KP, Tchernis R. Income, physical activity, sedentary behavior, and the 'weekend warrior' among U.S. adults. Prev Med. 2017:103:91-7.

5. Prevention CfDC. Differences in prevalence of obesity among black, white, and Hispanic adults: 2006-2008. MMWR: Morbidity and Mortality Weekly Report. 2009;58(27):740-4.

6. Prevention CFDC. Adult participation in aerobic and muscle-strengthening physical activities--United States. MMWR: Morbidity and Mortality Weekly Report. 2011;62(17):326-30.

7. Bellows-Riecken KH, Rhodes RE. A birth of inactivity? A review of physical activity and parenthood. Prev Med. 2008;46(2):99-110.

8. Dlugonski D, Motl RW. Social cognitive correlates of physical activity among single mothers with young children. Psychol Sport Exerc. 2014;15(6):637-41.

9. Chang MW, Nitzke S, Guilford E, Adair CH, Hazard DL. Motivators and barriers to healthful eating and physical activity among low-income overweight and obese mothers. J Am Diet Assoc. 2008;108(6):1023-8.

10. Young LE, Cunningham SL, Buist DS. Lone mothers are at higher risk for cardiovascular disease compared with partnered mothers. Data from the National Health and Nutrition Examination Survey III (NHANES III). Health Care Women Int. 2005;26(7):604-21.

11. Kegler MC, Haardörfer R, Alcantara I, Gazmararian JA, Gemma A, Reynolds $P$, et al. Home environments, physical activity, and energy expenditure among low-income overweight and obese women. Women Health. 2017:57(8):990-1006.

12. Chang M-W, Nitzke S, Buist D, Cain D, Horning S, Eghtedary K. I Am Pregnant and Want to Do Better But I Can't: Focus Groups with Low-Income Overweight and Obese Pregnant Women. Maternal and child health journal. 2014;19.

13. Sallis JF, Cervero RB, Ascher W, Henderson KA, Kraft MK, Kerr J. An ecological approach to creating active living communities. Annu Rev Public Health. 2006;27:297-322.

14. McLeroy KR, Bibeau D, Steckler A, Glanz K. An ecological perspective on health promotion programs. Health Educ Q. 1988;15(4):351-77.

15. Bauman AE, Reis RS, Sallis JF, Wells JC, Loos RJ, Martin BW. Correlates of physical activity: why are some people physically active and others not? Lancet. 2012;380(9838):258-71.

16. Sallis JF, Floyd MF, Rodríguez DA, Saelens BE. Role of built environments in physical activity, obesity, and cardiovascular disease. Circulation. 2012;125(5):729-37.

17. Brown PR, Brown WJ, Miller YD, Hansen V. Perceived constraints and social support for active leisure among mothers with young children. Leisure Sciences. 2001;23(3):131-44.

18. Thornton PL, Kieffer EC, Salabarría-Peña Y, Odoms-Young A, Willis SK, Kim $\mathrm{H}$, et al. Weight, diet, and physical activity-related beliefs and practices among pregnant and postpartum Latino women: the role of social support. Matern Child Health J. 2006;10(1):95-104.

19. Dunton GF, Liao Y, Intille S, Wolch J, Pentz MA. Physical and social contextual influences on children's leisure-time physical activity: an ecological momentary assessment study. J Phys Act Health. 2011;8(Suppl 1):S103-8. 
20. Shiffman S, Stone AA, Hufford MR. Ecological Momentary Assessment. Annu Rev Clin Psychol. 2008;4(1):1-32.

21. Hager ER, Tilton NA, Wang Y, Kapur NC, Arbaiza R, Merry BC, et al. The home environment and toddler physical activity: an ecological momentary assessment study. Pediatr Obes. 2017;12(1):1-9.

22. Black MM, Hager ER, Wang Y, Hurley KM, Latta LW, Candelaria M, et al. Toddler obesity prevention: A two-generation randomized attentioncontrolled trial. Matern Child Nutr. 2021;17(1):e13075.

23. Service FaN. Special Supplemental Nutrition Program for Women, Infants, and Children (WIC) 2021 [Available from: https://www.fns.usda.gov/wic.

24. Thomas S, Reading J, Shephard RJ. Revision of the Physical Activity Readiness Questionnaire (PAR-Q). Can J Sport Sci. 1992;17(4):338-45.

25. Hager ER, Gormley CE, Latta LW, Treuth MS, Caulfield LE, Black MM. Toddler physical activity study: laboratory and community studies to evaluate accelerometer validity and correlates. BMC Public Health. 2016;16(1):936.

26. Hager ER, Treuth MS, Gormely C, Epps L, Snitker S, Black MM. Ankle Accelerometry for Assessing Physical Activity Among Adolescent Girls: Threshold Determination, Validity, Reliability, and Feasibility. Res Q Exerc Sport. 2015:86(4):397-405

27. Dunton GF, Liao Y, Intille S, Huh J, Leventhal A. Momentary assessment of contextual influences on affective response during physical activity. Health Psychol. 2015;34(12):1145-53.

28. Sisson SB, Broyles ST, Newton RL Jr, Baker BL, Chernausek SD. TVs in the bedrooms of children: Does it impact health and behavior? Preventive Medicine: An International Journal Devoted to Practice and Theory. 2011;52(2):104-8.

29. Posada G, Lu T, Trumbell J, Kaloustian G, Trudel M, Plata SJ, et al. Is the secure base phenomenon evident here, there, and anywhere? A cross-cultural study of child behavior and experts' definitions. Child Dev. 2013;84(6):1896-905.

30. Hesketh KR, Goodfellow L, Ekelund U, McMinn AM, Godfrey KM, Inskip $\mathrm{HM}$, et al. Activity Levels in Mothers and Their Preschool Children. Pediatrics. 2014;133(4):e973.

31. Schoffman DE, Kaczynski AT, Forthofer M, Wilcox S, Hutto B, Child ST, et al. Longitudinal associations with changes in outdoor recreation area use for physical activity during a community-based intervention. Prev Med. 2015:78:29-32.

32. Lopez RP, Hynes HP. Obesity, physical activity, and the urban environment: public health research needs. Environ Health. 2006;5:25-

33. Shuval K, Hébert ET, Siddiqi Z, Leonard T, Lee SC, Tiro JA, et al. Impediments and facilitators to physical activity and perceptions of sedentary behavior among urban community residents: the Fair Park Study. Prev Chronic Dis. 2013;10:E177.

34. Warren JR, Hoonakker P, Carayon P, Brand J. Job characteristics as mediators in SES-health relationships. Soc Sci Med. 2004;59(7):1367-78.

35. Van Dyck D, Cerin E, De Bourdeaudhuij I, Hinckson E, Reis RS, Davey R, et al. International study of objectively measured physical activity and sedentary time with body mass index and obesity: IPEN adult study. Int J Obes (Lond). 2015;39(2):199-207.

\section{Publisher's Note}

Springer Nature remains neutral with regard to jurisdictional claims in published maps and institutional affiliations.
Ready to submit your research? Choose BMC and benefit from:

- fast, convenient online submission

- thorough peer review by experienced researchers in your field

- rapid publication on acceptance

- support for research data, including large and complex data types

- gold Open Access which fosters wider collaboration and increased citations

- maximum visibility for your research: over $100 \mathrm{M}$ website views per year

At BMC, research is always in progress.

Learn more biomedcentral.com/submissions 